\title{
SISTEM PENGATUR GORDEN PADA LAMPU BERBASIS PLC
}

\author{
Hartono Budi Santoso, Agoeng H. Rahardjo, Risa Utami Arsaf \\ Jurusan Teknik Konversi Energi - Politeknik Negeri Bandung \\ J1. Gegerkalong Hilir, Ds Ciwaruga - Bandung 40551 \\ Email: hartono@esi-labs.com
}

\begin{abstract}
When we leaving house in the empty situation which usually let the lamp on make wasting the energy we used and invited wickedness like robbing. Based on this situation the outhor create some device which give a savety when leaving house. Fungtion of this device are to control curtain and lamp automatically. So we can spit people that house not empty. The principle of this device is if user turn on the system with press the push button then at the sun rise curtain automatcally open and the lamp will off, and the other way curtain will automatically close and lamp will be on at the sunset. The system consists of two subsystem: motor and railway curtain track The whole system is controlled by PLC type OMRON CPM IA. LDR is a sensor to detect the light which places in out site room. Limit switch placed at the end of railway curtain track which used to stop the motor. After testing, we know that the system need 3 minutes for open the curtain and 5 minutes 20 second for close the curtain.
\end{abstract}

Key word : light sensor, PLC, Motor, Railway curtain track, Lamp

\section{PENDAHULUAN}

Aktifitas yang padat bagi manusia terkadang mengharuskan manusia itu sendiri untuk meninggalkan rumah dalam tempo yang cukup lama, dan biasanya ketika rumah ditinggalkan kosong lampu selalu berada dalam keadaan menyala. Hal ini dapat memboroskan energi listrik yang digunakan. Selain boros energi keadaan seperti ini dapat mengundang bahaya, karena orang akan dengan mudah mengetahui bahwa rumah itu kosong dan kemungkinan untuk terjadinya kejahatan (pencurian) sangat besar.

Atas dasar keadaan ini tentunya dapat diatasi dengan membuat suatu alat yang dapat mengatur lampu dan gorden secara otomatis. Pengaturan lampu bertujuan untuk menghemat energi listrik yang digunakan, sedangkan pengaturan gorden digunakan untuk memberi kesan bahwa rumah tidak dalam keadaan kosong. Dengan begitu rasa aman bagi manusia ketika meninggalkan rumah akan tercipta.

\section{PERANCANGANALAT}

a. Perangkat Elektronik

PerangkatElektronik meliputi :

\section{Power Suppy}

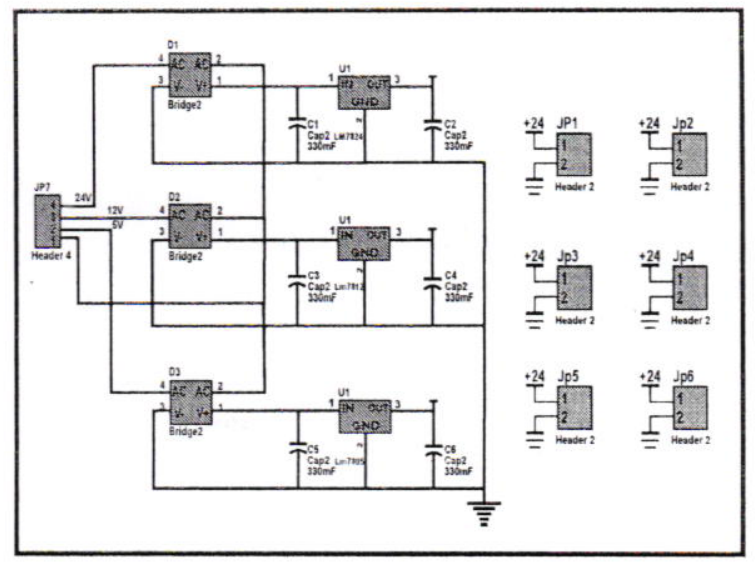

Gambar 1. Rangkaian Power Supply

Tegangan input yang dibutuhkan oleh rangkaian sensor yaitu sekitar $5 \mathrm{Vdc}$ dan $12 \mathrm{Vdc}$, sedangkan driver relay dan motor DC memerlukan tegangan input sebesar 24 Vdc. Rangkaian power supply ini terdiri dari sebuah transformator, tiga buah dioda bridge, enam buah kapasitor, dan tiga buah regulator masingmasing untuk output $5 \mathrm{Vdc}, 12 \mathrm{Vdc}$ dan $24 \mathrm{Vdc}$.

Transformator yang digunakan mempunyai arus sebesar yaitu 3 ampere. Sedangkan kapasitor yang digunakan enam buah kapasitor dengan nilai $330 \mu \mathrm{F} / 50 \mathrm{~V}$. Regulator yang digunakan untuk menghasilkan output $5 \mathrm{Vdc}$ yaitu LM7805, output 12 Vdc menggunakan LM7812, sedangkan untuk output $24 \mathrm{Vdc}$ menggunakan LM7824. 


\section{Sensor $L D R$}

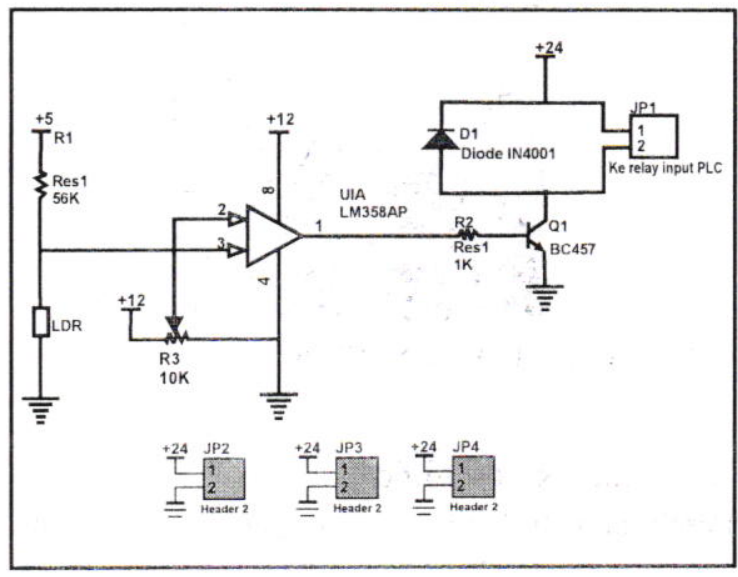

Gambar 2. Rangkaian sensor LDR

Sensor yang digunakan untuk mendeteksi cahaya yaitu LDR. Prinsip kerja sensor ini yaitu ketika sensor mendapatkan cahaya, maka resistansi LDR akan berubah menjadi kecil sehingga tegangan $5 \mathrm{Vdc}$ dari supply dapat mengalir ke IC LM358. IC LM358 merupakan Op-Amp yang berfungsi sebagai komparator. Tegangan pada pin 2 (inverting) akan dibandingkan dengan tegangan pada pin 3 (noninverting). RV $10 \mathrm{~K} \Omega$ berfungsi untuk mengatur besar tegangan pada pin 2. Jika pada keadan sensor tidak mendapatkan cahaya tegangan dari pin 2 akan lebih kecil dibandingkan dengan pin 3 sehingga akan ada tegangan output dari pin 1 . Tegangan ini digunakan untuk switching transistor yang akan menjadi input ke PLC.

Ketika transistor mendapatkan tegangan yang lebih dari tegangan nominal maka transistor berada pada kondisi saturasi. Daerah saturasi berada pada jangkauan $0 \mathrm{~V}<\mathrm{VCE}<0,7 \mathrm{~V}$. Pada daerah ini, titik kolektor berada pada kondisi bias maju (forward bias). Sehingga input tegangan 24 Volt akan mengalir untuk mengaktifkan relay atau kondisi "ON" yang kemudian akan menjadi input PLC (input PLC mendapatkan tegangan $24 \mathrm{~V})$. Sebaliknya apabila masukan driver tidak mendapatkan tegangan, maka transistor berada pada kondisi cut-off. Dioda digunakan untuk memproteksi transistor dari arus balik relay. Dioda yang digunakan yaitu tipe 1N4001 karena mudah didapatkan. Sedangkan relay yang digunakan adalah relay Omron MY2 dengan input 24 Vdc.
Driver motor DC dua arah putaran

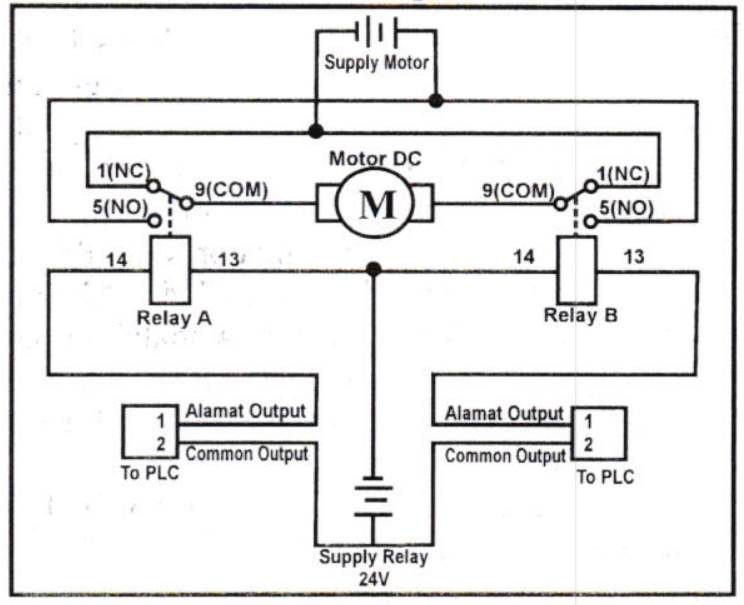

Gambar 3. Rangkaian Driver Motor Dua Arah Putar

Rangkaian driver dirancang untuk menggerakkan motor DC dengan dua arah putaran untuk menggerakkan gorden. Jika hanya relay $\mathrm{A}$ yang aktif maka motor $\mathrm{DC}$ akan berputar searah jarum jam $(\mathrm{CW})$, karena relay $\mathrm{A}$ dalam keadaan NO sedangkan relay B NC. Sebaliknya jika hanya relay B yang aktif maka motor berputar berlawanan jarum jam $(\mathrm{CCW})$, karena relay $\mathrm{A}$ dalam keadaan $\mathrm{NC}$ sedangkan relay $\mathrm{B}$ NO. Apabila tidak ada input dari alamat output PLC baik yang kanan maupun yang kiri, maka motor tidak akan bergerak, karena masingmasing kaki motor terhubung dengan GND. Kedua relay diaktifkan oleh PLC.

\section{Driver Lampu}

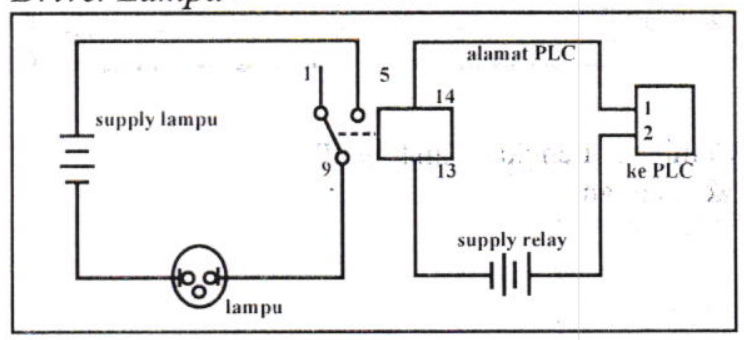

Gambar 4. Rangkaian Driver Lampu

Rangkaian driver ini digunakan untuk mengatur lampu dimana relay digunakan sebagai saklar yang terhubung dengan PLC, relay yang digunakan jenis OMRON 24 volt. Jika pada alamat output terminal PLC "ON" (diatur sesuai dengan program yang diberikan) maka tegangan $24 \mathrm{Vdc}$ yang terhubung pada common output akan mengaktifkan relay, sehingga akan ada perubahan mekanisme saklar otomatis dari NC ke NO yang kemudian beban (lampu) akan ON karena mendapatkan tegangan dari Vbeban. 


\section{Pengkabelan Input PLC}

Tiap-tiap PLC pada dasarnya merupakan sebuah mikrokontroller yang dilengkapi dengan peripheral yang dapat berupa masukan digital; keluaran digital atau relay. CPM1A 10 memiliki 4 output dan 6 input, indikator masukan dan keluaran, 4 macam lampu indikator, yaitu PWR, RUN, ERR/ALM, dan COMM. Alasan dipilihnya PLC OMRON CPM1A adalah sesuai dengan kebutuhan dan tersedia di Laboratorium Surya, Program Studi Teknik Konversi Energi POLBAN.

Alamat input PLC OMRON CPM 1A $10 \mathrm{I} / \mathrm{O}$ terdapat 6 alamat. Pada proyek akhir ini alamat input yang digunakan hanya 5 buah alamat, yaitu 000 sampai 004. Alamat ini digunakan untuk 2 buah saklar start dan stop, sensor $L D R$, dan 3 buah limit switch. Terdapat satu common untuk semua alamat input yang terhubung dengan +24 volt. Sedangkan push button, sensor LDR dan limit switch terhubung dengan supply GND dan alamat input PLC. Maka pengkabelan input yang digunakan adalah seperti pada Gambar 5.

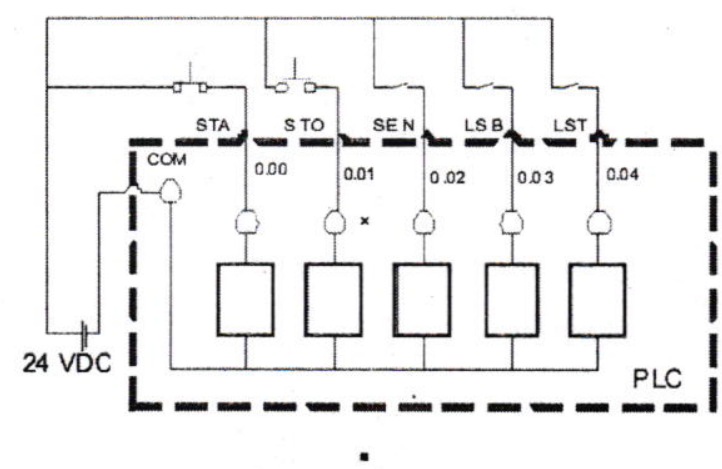

Gambar 5. Pengkabelan Input PLC

Keterangan :

STA: Tombol Start

STO : Tombol Stop

SEN : Sensor Cahaya

LSB : Limit Switch Buka

LST : Limit Switch Tutu

\section{b. Perancangan Mekanik}

Perancangan mekanik meliputi :

1. Mekanik Motor

Gerakan untuk menutup dan membuka gorden menggunakan motor gear $24 \mathrm{Vdc}$ sebagai penggerak dimana gear motor dipasang dengan ulir yang sesuai. Sebagai dudukan untuk motor menggunakan bahan plat besi.

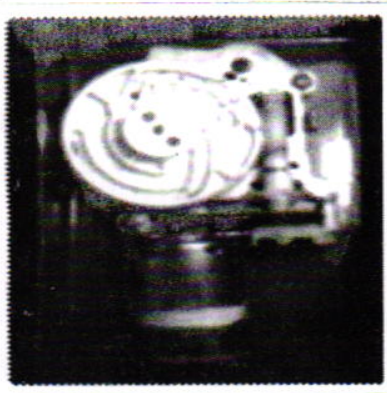

Gambar 6. Realisasi Motor Penggerak Gorden

\section{Mekanik Rel Gorden}

Pembuatan rel untuk penggerak gorden ini menggunakan rel gorden yang biasa di jual di pasaran dengan sistem tarik. Pada penelitian ini rel dimodifikasi dengan menambahkan plat besi yang dipasang vertikal. Fungsi dari plat besi ini yaitu untuk menekan limit switch sebagai pembatas gerakan motor.

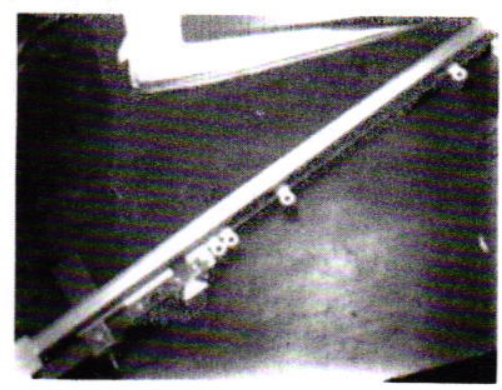

Gambar 7. Realisasi Rel Gorden

3. Desain Mekanik Pemasangan Rel pada Motor

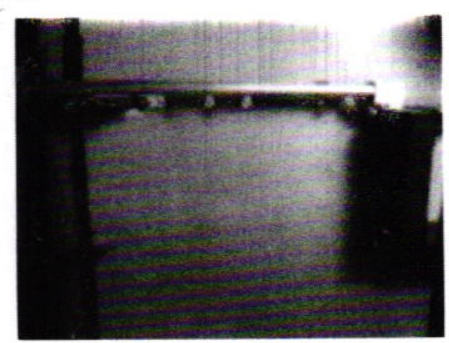

Gambar 8. Realisasi Pemasangan Rel pada Motor

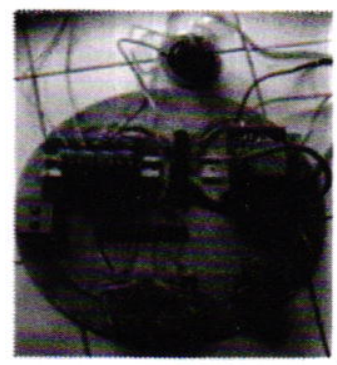

Gambar 9. Realisasi Kontrol PLC 


\section{c. Perancangan Perangkat Lunak}

Perancangan perangkat lunak dilakukan untuk memprogram PLC agar dapat digunakan sesuai dengan yang diharapkan. Dalam memprogram PLC terdiri dari dua cara yaitu dengan menggunakan komputer dan program console. Namun, pada perancangan ini komputer digunakan sebagai alat untuk memprogram PLC dengan menggunakan program Syswin 3.4. Bahasa pemograman yang digunakan adalah ladder diagram. Selanjutnya subbab ini akan membahas perancangan dan realisasi perangkat lunak termasuk penjelasan mengenai deskripsi kerja sistem, pengalamatan masukan dan keluaran PLC, serta diagram alir sistem otomatis.

\section{d. Perancangan Diagram Ladder}

Perangkat lunak merupakan pengendali dari perangkat keras, pada PLC bahasa pemograman yang umum digunakan yaitu menggunakan ladder diagram. Pembuatan program pada tugas akhir ini menggunakan Syswis 3.4, Gambar 10 merupakan flow chart sistem dan Tabel 1, 2, 3 dan 4 merupakan alamat - alamat inpuit output PLC.

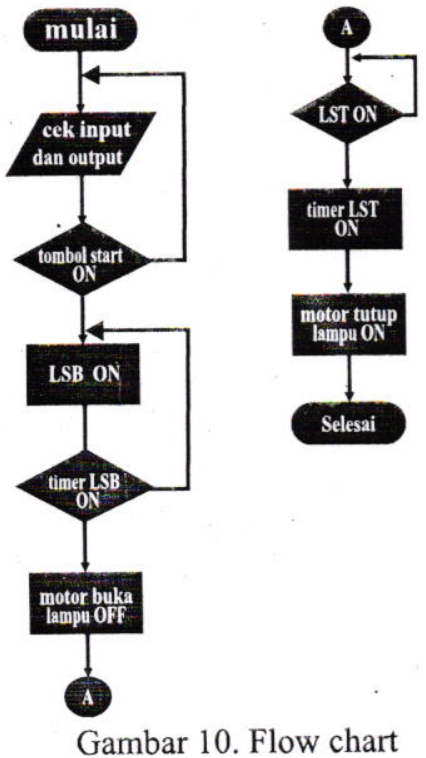

Tabel 1. Alamat input PLC

\begin{tabular}{|c|l|l|l|}
\hline No & Alamat & Masukan & \multicolumn{1}{|c|}{ Fungsi } \\
\hline 1 & 000 & START & Memulai \\
\hline 2 & 001 & STOP & Berhenti \\
\hline 3 & 002 & SEN & Sensor LDR \\
\hline 4 & 003 & LSB & $\begin{array}{l}\text { Limit Switch } \\
\text { Buka }\end{array}$ \\
\hline 5 & 004 & LST & $\begin{array}{l}\text { Limit Switch } \\
\text { Tutup }\end{array}$ \\
\hline
\end{tabular}

Tabel 2. Alamat output PLC

\begin{tabular}{|c|l|l|}
\hline No & Alamat & Output Motor DC \\
\hline 1 & 1000 & Motor Buka \\
\hline 2 & 1001 & Motor Tutup \\
\hline 3 & 1002 & Lampu ON \\
\hline
\end{tabular}

Table 3. Alamat output bayangan (Flag/Laching)

\begin{tabular}{|c|c|c|c|}
\hline No & Alamat & Nama & Fungsi \\
\hline 1 & 20000 & Flag 1 & Latch START \\
\hline
\end{tabular}

Tabel 4. State Diagram

\begin{tabular}{|c|c|c|}
\hline State & $\begin{array}{c}\text { Keadaan } \\
\text { On }\end{array}$ & Keterangan \\
\hline 0 & Semua Off & OFF \\
\hline 1 & $\begin{array}{c}\text { Motor Buka } \\
(\mathrm{MB})\end{array}$ & $\begin{array}{c}\text { TIM 3.SEN }=\text { ON } \\
\text { LST. MT }=\text { OFF }\end{array}$ \\
\hline 2 & $\begin{array}{c}\text { Mototr } \\
\text { Tututp (MT) }\end{array}$ & $\begin{array}{c}\text { TIM 0 }=\text { ON; } \\
\text { SEN.LSB.MB }=\text { OFF }\end{array}$ \\
\hline 3 & Lampu ON & SEN $=$ OFF. LSB $=$ ON \\
\hline
\end{tabular}

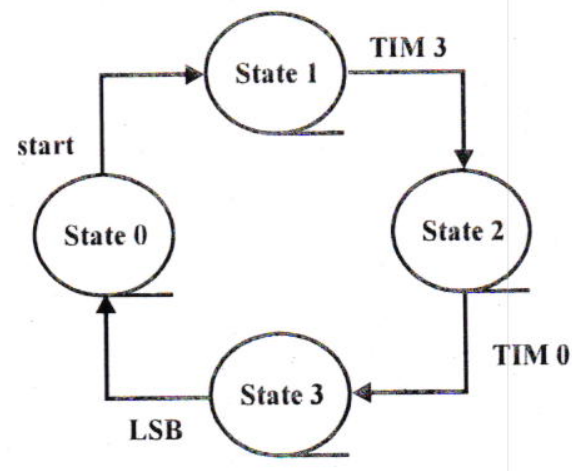

Gambar 11. State Diagram

\section{PENGUJAN DANANALISA \\ Metoda Pengujian}

Adapun pengujian sistem pada kodisi otomatis dilakukan sesuai dengan tahapan berikut:

1. Berikan tegangan $220 \mathrm{~V}$ AC pada panel supply dan PC.

2. Aktifkan PLC dengan menekan tombol STARTPLC.

3. Buka program Syswin 3.4 pada PC.

4. Download program yang telah dibuat di program Syswin 3.4, cek masukan dan keluaran yang telah dirancang pada program ke PLC.

5. Pastikan program pada Syswin 3.4 tetap dalam keadaan work online.

6. Run program. 
7. Cek dan càtat kondisi sistem.

8. Jika telah selesai, ubah mode run menjadi mode program.

9. Matikankondisi work online.

\section{Alat Bantu yang Digunakan}

Adapun alat-alat dan program yang digunakan dalam pengujian perangkat lunak ini adalah :

1. PLCOMRON SYSMAC CPM1A-10.

2. PC Processor Pentium 4 Dual Core, Memory $1 \mathrm{~GB}$, Hardisk 40GB, VGA 125 MB.

3. Perangkat lunak Syswin 3.4.

4. Power Supply DC $24 \mathrm{~V}, 12 \mathrm{~V} \& 5 \mathrm{~V}$.

\section{Pengujian dan Analisa Perangkat Keras}

Pengujian yang dilakukan meliputi beberapa bagian, yaitu bagian sensor LDR, rangkaian driver, pergerakan 2 arah motor DC.

\section{- Rangkaian Sensor LDR}

Rangkaian ini berfungsi sebagai pendeteksi ada tidaknya cahaya yang berasal dari matahari karena sensor ini diletakkan di luar. Sensor ini bekerja dalam dua kondisi, yaitu kondisi disinari atau tidak disinari, atau kondiai logic 1/0. Berikut ini adalah hasil pengukuran keluaran sensor LDR.

Tabel 5. Sensor LDR ketika diberi Cahaya

\begin{tabular}{|c|c|c|}
\hline Sensor & $\begin{array}{c}\text { Keluaran } \\
\text { (Logic) }\end{array}$ & $\begin{array}{c}\text { Vout } \\
\text { Terukur } \\
\text { (V) }\end{array}$ \\
\hline LDR & "l" & 10.3 \\
\hline
\end{tabular}

Tabel 6. Sensor LDR Ketika Tidak diberi Cahaya

\begin{tabular}{|c|c|c|}
\hline Sensor & $\begin{array}{c}\text { Keluaran } \\
\text { (Logic) }\end{array}$ & $\begin{array}{c}\text { Vout } \\
\text { Terukur (V) }\end{array}$ \\
\hline LDR & "0" & 0 \\
\hline
\end{tabular}

Berdasarkan kedua tabel di atas, maka bisa di analisa bahwa sensor $L D R$ bekerja dengan baik terhadap masukan cahaya.

\section{- Rangkaian Driver Relay}

Rangkaian driver merupakan rangkaian on-off yang menggunakan transistor yang berfungsi sebagai saklar. Rangkaian driver ini terdiri dari 4 input yang masing-masing outputnya berupa relay yang akan digunakan sebagai input PLC. Berikut hasil pengukuran yang didapatkan.

Tabel 7. Driver Relay

\begin{tabular}{|l|c|c|}
\hline \multirow{2}{*}{ Input (24 volt) } & \multicolumn{2}{|c|}{ Kondisi relay } \\
\cline { 2 - 3 } & Logic 0 & Logic 1 \\
\hline Relay 1 (sensor) & Tetap & $\mathrm{NC} \rightarrow \mathrm{NO}$ \\
\hline Relay 2 (Lampu) & Tetap & $\begin{array}{l}\mathrm{NC} \rightarrow \mathrm{NO}, \\
\mathrm{NO} \rightarrow \mathrm{NC}\end{array}$ \\
\hline Relay 3 (Motor Buka) & Tetap & $\begin{array}{l}\mathrm{NC} \rightarrow \mathrm{NO}, \\
\mathrm{NO} \rightarrow \mathrm{NC}\end{array}$ \\
\hline Relay 4 (Motor Tutup) & Tetap & $\begin{array}{l}\mathrm{NC} \rightarrow \mathrm{NO}, \\
\mathrm{NO} \rightarrow \mathrm{NC}\end{array}$ \\
\hline
\end{tabular}

Dari Tabel 7 di atas dapat diketahui bahwa driver relay dan relay bekerja dengan baik.

\section{Motor DC Bergerak Dua Arah Putaran}

Pergerakan motor DC dua arah dipakai pada bagian penggerak gorden, Berikut ini adalah hasil pengujian sistem.

Tabel 8. Kondisi Motor dan Waktu Respon

\begin{tabular}{|c|c|c|}
\hline \multirow{2}{*}{ Logic } & \multicolumn{2}{|c|}{ Kondisi Motor } \\
\cline { 2 - 3 } & Motor & waktu \\
\hline 01 & Buka & 3,00 menit \\
\hline 10 & Tutup & 5,20 menit \\
\hline
\end{tabular}

Dari Tabel 8 di atas diketahui bahwa motor bisa bergerak dua arah. Serta, dari lamanya waktu menunjukkan bahwa lama waktu buka dan tutup membutuhkan waktu yang berbeda.

\section{Pengujian dan Analisa Perangkat Lunak}

- Setting Program

Pengujian setting program dengan cara:

1. Menyalakan komputer.

2. Menyalakan modul PLC.

3. Mengcompile program ladder secara keseluruhan.

4. Mentransfer program dari PC ke PLC.

5. Menekan tombol start pada control board.

6. Melihat perubahan yang terjadi pada instruksi untuk setting program. 


\section{- Proses Kendali}

Pengujian untuk proses kendali dilakukan dengan cara:

1. Mengkompile program secara keseluruhan.

2. Mentransfer program dari PC ke PLC.

3. Menekan/memberikan ransangan pada bagian masukan PLC.

4. Mengamati perubahan yang terjadi pada ladder diagram.

5. Semua program yang terkait sudah dicompile di computer dan tidak ada yang erorr.

6. Mengamati proses eksekusi program yang terjadi dalam sistem sehingga didapatkan sistem kontrol yang sesuai dengan yang di inginkan.

\section{- Program ON-OFF}

Pengujian program on-off dilakukan untuk mengetahui bahwa program dapat terus berjalan setelah tombol start PLC ditekan. Program terdapat pada lampiran sedangkan hasil pengujian terdapat pada Tabel 9.

\section{Tabel 9. Hasil Pengujian Program $\mathrm{ON}$-OFF Sistem}

\begin{tabular}{|c|c|c|}
\hline $\begin{array}{c}\text { Aksi } \\
\text { PLC aktif }\end{array}$ & $\begin{array}{c}\text { Reaksi } \\
\text { push button start on, } \\
\text { maka } \\
\text { program dapat } \\
\text { dijalankan. } \\
\text { - Indikator start } \\
\text { PLC pada panel } \\
\text { nyala. }\end{array}$ & sesuai \\
\hline $\begin{array}{c}\text { Tombol stop } \\
\text { PLC aktif }\end{array}$ & $\begin{array}{c}\text { - push button start off, } \\
\text { maka } \\
\text { program tidak } \\
\text { dapat dijalankan. } \\
\text { Indikator stop PLC } \\
\text { pada panel nyala }\end{array}$ & sesuai \\
\hline
\end{tabular}

Berdasarkan Tabel 9, jika program di atas dijalankan maka push button start akan tetap on hanya dengan sekali picuan dari tombol start. Hal ini dikarenakan status keluaran 200.00 diparalel dengan tombol start tersebut untuk menyimpan status on. Kemudian diseri dengan tombol stop agar saat tombol stop on, maka akan memutuskan status keluaran maupun tombol start. Kemudian Flag tersebut akan menjadi awalan dari seluruh program pada sistem. Seperti yang terlihat pada gambar ladder diagram dibawah ini.

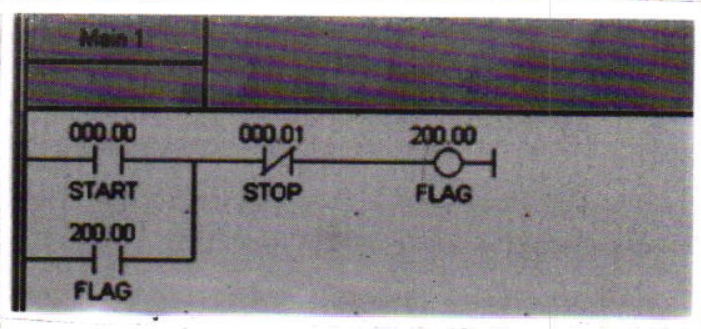

Gambar 12.Ladder Diagram Program Start-Stop

- Program Penggerak Motor

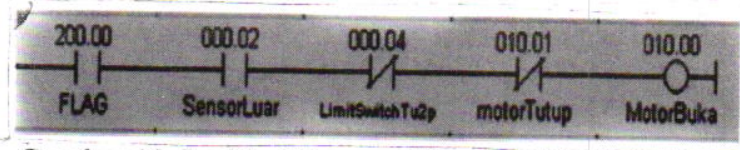

Gambar 13. Ladder Diagram Program Motor Buka

Pada saat tombol Start ON maka Flag (Output Bayangan) pada alamat 200.00 akan ON, kemudian Flag tersebut akan menjadi awalan dari seluruh program pada system. Syarat motor buka yaitu ketika sensor luar mendapatkan cahaya, limit switch tutup tidak ditekan dan motor tutup mati. Pada keadaan ini motor akan berputar searah jarum jam.

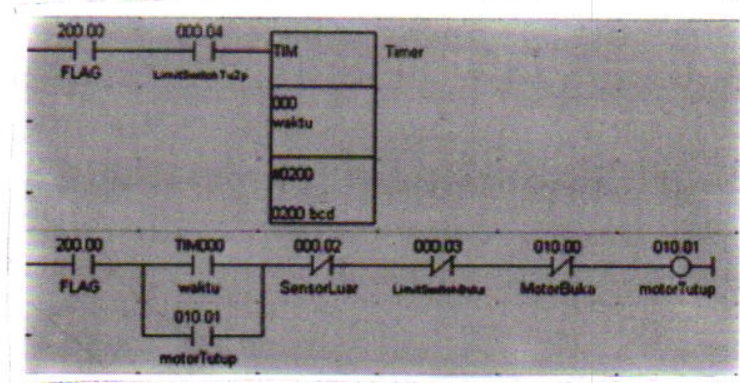

Gambar 14. Ladder Diagram Program Motor Tutup

Kondisi untuk motor tutup ini tidak jauh berbeda dengan kondisi pada motor buka. berhentinya motor buka yaitu pada saat limit switch tutup ditekan. Limit switch yang di tekan ini akan mengaktifkan timer yang kemudian dijadikan sebagai pemucu untuk motor tutup. Syarat dari motor tutup ini adalah TIM 000 yang merupakan alamat timer dari limit switch tutup aktif, sensor tidak mendapatkan cahaya, limit switch tidak ditekan dan motor buka mati. Motor ini akan bergerak hingga limit switch buka ON. Pada keadaan ON motor akan bergerak berlawanan dengan jarum jam 
- Program Lampu

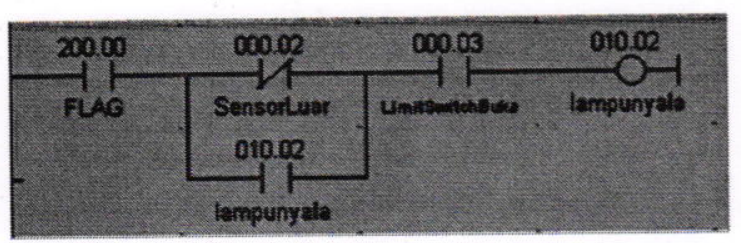

Gambar 15. Ladder Diagram Program Lampu Menyala

Lampu akan menyala apabila sensor LDR tidak mendapatkan cahaya dan ketika limit switch buka On. Kemudian lampu akan mati jika sensor LDR mendapatkan cahaya dan limit switch buka.

\section{Analisis Proses Kerja Alat Secara Keseluruhan}

Dalam keadaan ON, ketika malam hari sensor LDR tidak mendapatkan cahaya dan motor penggerak gorden akan berputar berlawanan dengan jarum jam, hal ini terjadi karena motor bergerak mundur, kemudian motor akan berhenti apabila telah menekan limit switch buka dan dengan seketika lampu akan menyala. Sebaliknya dalam keadaan pagi hari sensor akan mendapatkan cahaya dan motor akan bergerak maju searah dengan jarum jam hingga menyentuh limit switch tutup dan berhenti. Ketika motor bergerak maju secara otomatis limit switch buka akan OFF dan mematikan lampu.

\section{KESIMPULAN}

Dari hasil uraian dan pengujian Tugas akhir ini dapat diambil beberapa kesimpulan, yaitu

- Realisasi alat berjudul Sistem Pengatur Gorden dan Lampu Berbasis PLC dapat dilaksanakan sesuai dengan batasan masalah dan spesifikasi yang telah ditetapkan oleh perancang.

- Waktu yang dibutuhkan untuk membuka gorden adalah 3 menit

- Waktu yang dibutuhkan untuk menutup gorden adalah 5 menit 20 detik

\section{DAFTAR PUSTAKA}

1. 1997. A Beginner's Guide To PLC. Omron Asia Pacific PTE. Ldt

2. Putra, Eko Agfianto, 2004. PLC Konsep, Pemrograman dan Aplikasi. Edisi pertama, Gava Media, Yogyakarta

3. . http://www.wikipedia.com. 28 Mei 2010. 20.12 WIB 